\section{(6) OPEN ACCESS}

Professor Nir Eyal, Department

of Global Health and Population, Harvard TH Chan

School of Public Health, 651

Huntington Ave., FXB Building,

Boston, MA 02139, USA;

neyal@hsph.harvard.edu

Received 1 February 2016 Accepted 8 February 2016 Published Online First 23 May 2016

\section{Linked}

- http://dx.doi.org/10.1136/ medethics-2016-103416

\section{CrossMark}

To cite: Eyal N. J Med

Ethics 2017;43:65-66.

\title{
The benefit/risk ratio challenge in clinical research, and the case of HIV cure: an introduction
}

\author{
Nir Eyal
}

\section{ABSTRACT}

This piece introduces the JME symposium 'The benefit/ risk ratio challenge in clinical research, and the case of HIV cure.'

In memory of Alan Wertheimer, 1942-2015, who sought an examined research ethics

There is now hope to find a cure for HIV someday, or at least to accomplish long-term remission of the virus absent antiretroviral treatment (ART). Timothy Brown, the 'Berlin Patient', appears to have been completely cured of HIV. Six years after a curative intervention, Brown has no detectable level of the virus, and no need for ART. Patients undergoing a variety of other interventions in France, Boston, and Mississippi developed stable remission of the virus without taking antiretrovirals, typically until a final viral rebound.

While continued ART nearly eliminates morbidity and markedly prolongs life for people living with HIV, ART is treatment, not a cure. Under ART, the virus persists indefinitely in latent reservoirs in the patient's body; upon ART interruption, it rebounds. And even under ART, some co-morbidities, stigma, costs, and burdens continue to affect patients, and life-long treatment cost prevents adequate coverage for the 35 million people living with HIV. ${ }^{12}$

An emphasis area for the International AIDS Society and the US National Institutes of Health, work toward a cure and long-term sustainable remission of HIV is currently the focus of 19 completed studies and at least 35 ongoing or planned ones. ${ }^{3}$ Complementing old, recent, and planned treatment and prevention strategies to fight HIV, these clinical studies work toward the development of either:

1. A literal 'cure' (sometimes called a sterilising cure), namely, eradication of all replicationcompetent HIV in a patient's body, or:

2. 'Long-term remission', that is, the absence of viral rebound after ART cessation for a period of several years. ${ }^{1}$

But progress toward a cure and long-term remission comes with a serious ethical challenge. ${ }^{4-6}$ Many early-phase cure and remission studies would impose substantial risks, uncertainties, and invasive procedures on some participants. Some studies include interventions with high mortality, such as stem cell transplantation. Some include interventions never before tested in (immunocompromised) patients, which are therefore shrouded in complete uncertainty. Some necessitate a clinically-unnecessary interruption of ART in patients who are doing well on ART, potentially leading to morbidity or ART resistance. Some require invasive and clinically-unnecessary exams and biopsies, for example, ones to identify the internal tissue in which latent HIV reservoirs are hiding away from the impact of ART.

In many areas of medicine, early-phase studies to characterise toxicity and pharmacokinetics involve risks and, very rarely, severe adverse events, ${ }^{7}$ with only little hope for clinical effect. But the challenge in HIV cure studies is special. Many patients who consider joining risky early-phase studies for cancer, for instance, are doing poorly, arguably with sound reason to try just about anything. HIV patients tend nowadays to have good alternatives to study participation, namely, remaining on ART. While being cured without side effects would be even better than remaining on ART, severe side effects may accompany having been cured and even without side effects, being cured does not seem medically far superior to being stable on standard ART - to taking one pill a day with small expected morbidity; the superiority of mere durable remission to remaining stable on ART is even smaller.

Compare the use of stem cell transplantation in early-phase HIV cure studies to its occasional use in early-phase studies for chronic diseases with little short-term mortality, such as sickle cell disease, ${ }^{8}$ Type I diabetes, ${ }^{9}$ chronic granulomatous disease, ${ }^{10}$ and thalassaemia. ${ }^{11}$ Use of life-risking stem cell transplantation for these chronic diseases was often controversial. While untreated HIV clearly results in serious morbidity and mortality, these chronic diseases may well involve greater morbidity than HIV managed with ART. Since the use of stem cell transplantation for managing these chronic diseases was controversial, its use, and the use of other high-risk strategies, in HIV cure and remission studies pose a serious challenge.

Differently put, a small chance of a slight improvement, accompanied by a greater chance of gaining nothing or being severely burdened or harmed, seems on the face of it like a bad 'gamble' for patients. It fails to maximise their medical prospects. A decision to join some early-phase HIV cure and remission trials may appear irrational for patients who are doing well on ART.

Hence, an ethical challenge. We want to identify and hone cure and remission strategies for HIVwe owe as much to patients. But to do so we need study participants, and we must treat these particular patients right too. Is there a way to make trial 
participation an advantageous 'gamble' for all cure study participants? If not, can these studies remain ethical?

This is not the sheer pragmatic challenge, of how to convince enough patients to join cure- and remission studies. In a recent survey of American HIV patients, a majority expressed willingness to participate in all 14 types of HIV cure study. ${ }^{12}$ Though the per cent who would be willing and able to participate will be much smaller for any actual study, early-phase studies require only few participants. Nor is our challenge simply the ethical concern that, subjectively, patients might not fully comprehend the risks of study participation, or that they must be overestimating the medical benefits to them, so they are choosing a perfectly advantageous option non-autonomously.

The challenge is both ethical and objective. It is the concern that in many early-phase HIV cure and remission studies, a standard requirement in research ethics for a favourable benefit/ risk ratio is transgressed. ${ }^{13-15}$ Are we giving candidate participants a fair 'bargain'? Or are we inviting them to substitute what are objectively rather good medical prospects by worse ones? And if that is what we do when we conduct some earlyphase cure and remission studies, are we acting wrongfully, or is this to some degree our prerogative given the vast global need for these interventions? Could we do things differently in these studies and in their administration, to keep them robustly ethical?

Call this the benefit/risk ratio challenge in early-phase HIV cure- and remission studies. ${ }^{5}$ Addressing this challenge is the business of contributions to this JME symposium, guest edited by ethicist Nir Eyal. Discussing a breadth of strategies for coping with this challenge turns out to cast light not only on the way forward in HIV research, but on the philosophical foundations of research ethics in general: What is an acceptable deal for the individuals who participate in our clinical studies? What is unacceptable, even in studies that advance science, healthcare, and human welfare?

The symposium starts with a descriptive background. Cure researcher Daniel Kuritzkes makes the fuller case for seeking a cure for HIV while laying out some of the serious risks to study participants in many early-phase HIV cure studies. HIV clinicians and investigators Paul Sax and Kenneth Freedberg provide greater detail on the likelihood of specific curative strategies, if found effective and safe, to become cost-effective and potentially scalable on a population level. A third piece, by the symposium editor, outlines the rest of the discussion. It catalogues candidate ethical solutions for the benefit/risk ratio challenge to early-phase HIV cure and remission studies. In so doing, it also presents the rest of the symposium. Consequent sections discuss some candidate solutions to the challenge. A short afterward notes wider implications for research ethics.

Acknowledgements This symposium is based on a workshop held at Harvard Medical School in May 2015. For the introduction, I wish to thank workshop participants and Steve Joffe for helpful ideas, and Regina Edifor, for web searches.

Funding This work was funded by NIAID grants 1 R01 Al114617-01A1 and 1 R56 Al114617-01, both titled 'HIV cure studies: risk, risk perception, and ethics'.

Competing interests None declared.

Provenance and peer review Not commissioned; internally peer reviewed.

Open Access This is an Open Access article distributed in accordance with the Creative Commons Attribution Non Commercial (CC BY-NC 4.0) license, which permits others to distribute, remix, adapt, build upon this work non-commercially, and license their derivative works on different terms, provided the original work is properly cited and the use is non-commercial. See: http://creativecommons.org/ licenses/by-nc/4.0/

\section{REFERENCES}

1 International AIDS Society. Global Scientific Strategy Towards an HIV Cure 2016: IAS, forthcoming 2016.

2 UNAIDS. UNAIDS report on the global AIDS epidemic, 2013.

3 NIH. Clinical Trials.gov 2016 [Available from: http://www.ClinicalTrials.gov.

4 Lo B, Grady C, Working Group on Ethics of the International AIDS Society. Ethical considerations in HIV cure research: points to consider. Curr Opin HIV AIDS 2013:8:243-9.

5 Eyal N, Kuritzkes DR. Challenges in clinical trial design for HIV-1 cure research. Lancet 2013;382:1464-5.

6 Evans D. What Would You Do to Cure HIV? POZ, 2011.

7 Chan S. 6 Hospitalized, One of Them Brain-Dead, After Drug Trial in France. New York Times 2016.

8 Kodish E, Lantos J, Stocking C, et al. Bone marrow transplantation for sickle cell disease. A study of parents' decisions. New England J Med 1991;325:1349-53.

9 Voltarelli JC, Couri CE, Stracieri AB, et al. Autologous nonmyeloablative hematopoietic stem cell transplantation in newly diagnosed type 1 diabetes mellitus. JAMA 2007;297:1568-76.

10 Kang EM, Marciano BE, DeRavin S, et al. Chronic granulomatous disease: overview and hematopoietic stem cell transplantation. J Allergy Clin Immunol 2011;127: 1319-26; quiz 27-8.

11 Caocci G, Pisu S, Argiolu F, et al. Decision-making in adult thalassemia patients undergoing unrelated bone marrow transplantation: quality of life, communication and ethical issues. Bone Marrow Transplant 2006;37:165-9.

12 Dubé K, Taylor J, Evans D, et al. Emerging Results of an Extensive Survey of Potential Participants' Willingness to Participate in HIV Cure Research in the United States. 7th International Workshop on HIV Persistence during Therapy. Miami, FL, 2015.

13 National Commission for the Protection of Human Subjects of Biomedical and Behavioral Research. The Belmont Report 1998. http://www.fda.gov/oc/ohrt/RBS/ belmont.html

14 HHS. 45 CFR 46 (Human subjects research). USA, 2009.

15 Emanuel EJ, Wendler D, Grady C. What makes clinical research ethical? JAMA 2000;283:2701-11. 